\title{
Seemingly Unrelated Regression Equations for Developing a Pavement Performance Model
}

\author{
Ciro Caliendo ${ }^{1}$, Maurizio Guida ${ }^{2} \&$ Emiliana Pepe $^{2}$ \\ ${ }^{1}$ Department of Civil Engineering, University of Salerno, Italy \\ ${ }^{2}$ Department of Information Engineering, Electrical Engineering, and Applied Mathematics, University of \\ Salerno, Italy \\ Correspondence: Ciro Caliendo, Department of Civil Engineering, University of Salerno, Via Giovanni Paulo II, \\ 132, Fisciano, Salerno 84084, Italy. Tel: 39-89-964-140. E-mail: ccaliendo@unisa.it
}

Received: September 14, 2015

doi:10.5539/mas.v9n13p199
Accepted: October 9, 2015

Online Published: November 30, 2015

URL: http://dx.doi.org/10.5539/mas.v9n13p199

\begin{abstract}
The paper presents a joint analysis of some pavement performance indicators based on a system of seemingly unrelated regression equations (SURE) which allows to handle correlated error terms. In particular, three major indicators such as the side friction coefficient $\left(\mathrm{SFC} 20^{\circ} \mathrm{C}\right)$, mean-profile depth (MPD), and international roughness index (IRI), were measured in a case study and subsequently used in analysis. Regression parameters were estimated by the Maximum Likelihood Method and the t-statistic was considered to show the statistical significance of regression coefficients. The results show that estimation points have the signs expected: the $\mathrm{SFC}_{20^{\circ} \mathrm{C}}$ decreases as the number of accumulated trucks $\left(N_{\mathrm{t}}\right)$ increases; whereas the MPD and IRI increase as the number of trucks increases. A likelihood ratio test was also carried out to determine whether the system model, which assumes correlation among error terms, was more appropriate than separate models. In this particular case, with three degrees of freedom, was found that the result corresponds to a $p$-value 0.150 and the null hypothesis cannot be rejected at any significance level less than this value.
\end{abstract}

Keywords: pavement performance, sideway force coefficient, international roughness index, sensor measured texture depth, seemingly unrelated regression equations

\section{Introduction}

Physical measures of road conditions are often used as a basis for determining safety needs, rehabilitation requirements and resource allocation. For Italian motorways, among various pavement-functionality measures, the Sideway Force Coefficient (SFC), the International Roughness Index (IRI), and the MPD (Mean Profile Depth) are parameters that play a significant role for forecasting the performance of a pavement over time.

The SFC is used to describe the friction between the vehicle tyre and pavement. It is defined as the ratio between the tangential force divided by the normal force at a standard speed. This parameter is expressed numerically by positive values smaller than 1 (or smaller than 100 in some official reports where its value has been multiplied by 100 ). The SFC is generally thought to be above all associated to road safety.

The IRI is used to describe a characteristic of the longitudinal profile of a travelled wheel track. It is based on the ratio of a standard vehicle's accumulated suspension motion divided by the distance travelled by the vehicle during the measurement. The IRI, which is expressed in $\mathrm{m} / \mathrm{km}$ ( or $\mathrm{mm} / \mathrm{m}$ ), is generally considered to be a standardized roughness measurement that is correlated more especially with vertical passenger acceleration (a measure of ride quality).

The MPD, which is a measure of the macrotexture of pavement surface evaluated by means of a laser, is generally expressed in $\mathrm{mm}$ and appears to influence in particular tire and road noise, as well as friction.

The aforementioned three measures of pavement performance are often thought to be correlated to each other. For example decreases in sideway force coefficient are usually considered to be accompanied by increases in international roughness index and/or increases in the mean depth of texture profile. Additionally, it is to be said that different indicators when are used separately capture only one aspect of the performance of a pavement. The need to show the interrelation among different indicators while accounting for the full performance of a pavement over time have stimulated researchers in the development of interesting statistical models, which is 
within the scope of this paper.

A wide range measures can be found in the international literature to evaluate pavement condition, such as more especially: (i) friction, (ii) roughness, (iii) rutting, (iv) fatigue cracking, (v) surface deflection. In addition numerous methodologies have been used to account for the pavement performance over time. However, the majority of these studies, which are generally based on regression models that correlate the dependent variable (performance indicator) to explanatory variables (typically including traffic, weather conditions and/or structural strength), consider only a performance indicator or each performance indicator investigated is assumed in analysis to be unrelated to other ones. In keeping with the studies of last decade, for example, Loprencipe \& Cantisani (2013) apply an unified analysis both for surveys and processing of acquired data with the aim to represent the pavement surface characteristics. Archilla \& Madanat (2001) use a methodological approach based on a joint estimation that combines the information from two different data sources in order to develop a rutting model of pavement. Prozzi \& Madanat (2004), involve the multivariate regression for combining experimental and field data to predict pavement roughness progress. Cantisani \& Loprencipe (2010) investigate on the correlations between roughness and road users' comfort. Archilla (2006) proposes a rutting model that is a modification from the one presented by Archilla \& Madanat (2001). In particular they apply a methodological approach which allows some model parameters to vary randomly, in contrast with the assumption that parameters are constant across observations. By using this methodology they find different results from other simpler models that ignore the unobserved heterogeneity or attempt to capture it through a mixed-effects approach. In this respect, it is to be remembered that a mixed-effects approach is a combination of fixed and random-effects where only the model intercept is allowed to vary randomly, while the other parameters are fixed in model (see Hilbe, 2007; Greene, 2003; Greene, 2007; Caliendo et al., 2015; for greater in-depth knowledge about the random-intercept model which is known in the literature to be equivalent to random-effects one). Onar et al. (2006) show that the mixed-effects models are useful in analysing pavement performance from accelerated pavement testing (APT) based on rut depth. Puccinelli \& Jackson (2007) combining environmental and structural factors and by using multivariate regression procedures develop individual models of fatigue, rutting, and roughness, respectively. The American Association of State Highway and Transportation Official (2008) in the more recent version method of pavements design, which is known as the Mechanistic-Empirical Pavement Design Guide (MEPDG), also proposes individual models of fatigue, rutting, and roughness. However, the MEPDG requires to designers to recalibrate the coefficients of the distress models depending on local conditions. In this respect, Caliendo (2012) has recalibrated these coefficients for the design of flexible pavements in Italy. Khraibani at al. (2012) use the mixed-effects models for providing an evolution law of pavement deterioration based on cracking. Fini \& Parast (2012) use the multivariate regression analysis to compare the effect of some variables (age, temperature, freezing index, and surface thickness) on the progression of pavement roughness. Loprencipe et al. (2015) consider performance parameters to set a global assessment method of road distresses.

Despite the significant contribution to the state-of-the art in pavement performance modelling over time, the aforementioned studies present a limitation consisting more especially in the fact that the proposed models are based on individual performance indicators not correlated to each other. It is to be stressed that one type of indicator does not sufficiently capture the overall performance of a pavement, as a consequence more indicators should be used and these should be jointly involved in regression models in order to fully reflect the progress of deterioration mechanism. With regard to this, Prozzi \& Hong (2008) present a statistical approach to jointly account for the performance of a pavement based on two different indicators, such as roughness and rut depth. In particular a statistical regression system is presented to capture the deterioration process in terms of these two indicators considered simultaneously in analysis with correlated error terms. The proposed regression system is currently denoted in the literature as the seemingly unrelated regression estimation (SURE) technique. The SURE approach, which appears to have been originally developed by Zellner (1962), accounts for the correlation among the error terms in each seemingly unrelated equation in order to improve the parameter estimates. In fact, the independence assumption of error terms might not be valid because the indicators describing different deterioration are from the same road section and thus likely to share some unobserved characteristics. Therefore, it is more realistic to incorporate in the analysis the correlation among equations. Greater knowledge about this subject can be found more especially in Wooldridge (2002), Greene (2003), Greene (2007), Washington et al. (2011).

Applications of the SURE technique to pavement performance indicators can be found also in Anastasopoulos et al. (2009), where the fixed-parameters SURE is used for mathematically resolving a system of four pavement condition variables with correlated error terms. Subsequently to the aforementioned paper, Anastasopoulos et al. (2012) make one step further in research by using the random-parameters SURE to account for both the 
correlation that exists among pavement-performance measures and the heterogeneity across observations. The unobserved heterogeneity may be due to the fact that information related to factors known to affect the performance measures might not be available in databases. This extension of the SURE technique has been applied to four performance indicators simultaneously considered; such as roughness, pavement condition rating, rut depth, and deflection. More specifics on the random-parameters SURE can be found above all in Singh \& Ullah (1974).

Although the use of the SURE approach represents a significant development in research concerning the progress of pavement deterioration over time, the possibility to account for the pavement performance based on the three indicators jointly applied such as the aforementioned SFC, IRI, and MPD taking into account the correlation among error terms does not appear to have been investigated in depth. Additionally, it is to be said that local input data for traffic, climate, and materials, which in Italy are different from those used in studies of other countries, do not seem to have been hitherto implemented in the SURE technique. There is an a priori reason for believing that the transferability of results to a geographic area different from that in which the results have been obtained may present problems because they are based on local conditions that are different from those of the place that is being studied. Moreover, it is to be said that the use of asphalt porous instead of traditional bituminous mixture in the surface layer of pavement has not yet been sufficiently investigated. As a result, there are at least three reasons to justify this paper. The first is motivated by the need to use the SURE technique to pavement performance considering that the contemporaneous measurements of the SFC, IRI, and MPD might be affected by correlated error terms. The second is for applying this technique to local conditions. The third is for showing the results when a porous asphalt is used.

In the light of the previous considerations, the main objective of the current paper is to make an additional development to the state of knowledge by applying the SURE technique at Italian conditions. For this purpose the paper is organized as follows: the next section contains the description of the data set of a case study regarding an Italian motorway section. In particular the SFC, IRI and MPD indicators are measured on a porous asphalt pavement over time. The third section presents the statistical methodology used. Then the results are presented and discussed. Finally the conclusions and directions for future research are reported.

\section{Data Description}

The monitored motorway, which is a four-lane median-divided road, is located in the South of Italy, connecting the cities of Salerno and Reggio Calabria (marked as the A3 motorway). Three performance indicators of pavement known as the side force coefficient (SFC), the international roughness index (IRI), and the mean profile depth (MPD) were more especially measured in three different time periods on a same section of this motorway. For this aim, the ERMES (Equipment for Routine evaluation of Macro-texture, Evenness and Skid resistance) was used. The ERMES, which is a SCRIM (Side force Coefficient Road Inventory Machine) plus a multifunctional equipment, is an instrumented vehicle that travels on the road at a standard speed $(60 \mathrm{~km} / \mathrm{h})$ for surveying simultaneously the three aforementioned performance indicators. Since these indicators are measured contemporaneous by the same machine, the correlation among error terms might be expected.

The SFC, IRI, and MPD were surveyed in years 2007, 2010, and 2012, on a same road section of the motorway investigated along the direction north of right lane (prevalently interested by trucks). This motorway section is $3.6 \mathrm{~km}$ long and its longitudinal position is from the $\mathrm{km} 32+010$ to $\mathrm{km} 35+610$. Longitudinal measurements repeated in the aforementioned three years are used in analysis. The values of these measurements, which are collected every $10 \mathrm{~m}$, were extracted from the official reports of the Motorway Management Agency (MMA). For each data also a variety of details were recorded, including more especially date and spatial location of measurement, as well as pavement temperature. In this respect, it is to be said that a temperature adjustment factor is also applied by the Motorway Management Agency to take into account the effects of pavement temperature on the measurement of the SFC. Then, values of the SFC at a standard temperature of $20^{\circ} \mathrm{C}$ $\left(\mathrm{SFC}_{20^{\circ} \mathrm{C}}\right)$, which are computed and reported directly in these official documents of the MMA, were more especially used in analysis. With reference to the IRI and MPD, because the values of these indicators might be scarcely influenced by temperature, no adjustment factor is provided by the MMA. In the light of these considerations, the number of observations for each of the three mentioned indicators $\left(\mathrm{SFC}_{20^{\circ} \mathrm{C}}\right.$, IRI, and MPD) measured on the motorway section investigated is equal to 360 for each of the three aforementioned years. Summary statistics of these three performance indicators are given in Table 1. 
Table 1. Summary statistics of performance indicators

\begin{tabular}{cccccccccccccccccc}
\hline \multicolumn{4}{c}{ Sideway Force Coefficient (SFC) at $20^{\circ} \mathrm{C}$} & \multicolumn{3}{c}{ Mean Profile Depth (MPD) $[\mathrm{mm}]$} & \multicolumn{2}{c}{ International Roughness Index (IRI)[mm/m] } \\
\hline Year & Mean & Mode & $\begin{array}{c}\text { Standard } \\
\text { deviation }\end{array}$ & Min & Max & Mean & Mode & $\begin{array}{c}\text { Standard } \\
\text { deviation }\end{array}$ & Min & Max & Mean & Mode & $\begin{array}{c}\text { Standard } \\
\text { deviation }\end{array}$ & Min & Max \\
2007 & 55.34 & 58.04 & 3.30 & 42.56 & 60.94 & 1.38 & 1.38 & 0.10 & 0.96 & 1.62 & 2.22 & 1.82 & 1.29 & 0.80 & 9.04 \\
2010 & 54.51 & 58.00 & 4.50 & 36.00 & 64.00 & 1.62 & 1.63 & 0.11 & 1.01 & 2.58 & 2.41 & 1.90 & 1.39 & 0.80 & 8.90 \\
2012 & 43.72 & 45.00 & 3.22 & 34.00 & 51.00 & 1.64 & 1.69 & 0.17 & 0.93 & 2.39 & 2.67 & 2.10 & 1.00 & 0.80 & 7.60 \\
\hline
\end{tabular}

The measurements of these performance indicators resulted to be correlated. Table 2 shows that there is a negative relationship between the SFC $20^{\circ} \mathrm{C}$ and MPD, as well as between the SFC $20^{\circ} \mathrm{C}$ and IRI; whereas a positive relationship exists between the MPD and IRI. This means that to a decrease of friction over time is associated to an increase both of profile depth and roughness; whereas as profile depth increases also roughness increases. Accounting for these correlations is an important concern in selecting of an appropriate statistical methodology.

Table 2. Correlation coefficients of the pavement performance indicators

\begin{tabular}{cccc}
\hline & SFC at $20^{\circ} \mathrm{C}$ & MPD $[\mathrm{mm}]$ & IRI $[\mathrm{mm} / \mathrm{m}]$ \\
\hline Sideway Force Coefficient (SFC) at $20^{\circ} \mathrm{C}$ & 1 & & 1 \\
Mean Profile Depth (MPD) $[\mathrm{mm}]$ & -0.491 & 0.206 & 1 \\
International Roughness Index (IRI) $[\mathrm{mm} / \mathrm{m}]$ & -0.351 & 1 \\
\hline
\end{tabular}

Traffic data and the percentage of trucks were also extracted from the official reports of the MMA. On the basis of the available traffic data, the authors estimated the annual average daily traffic (AADT) for one travel direction at years 2007, 2010, and 2012 that was found to be respectively of 21786; 22324; and 22682 vehicles per day. The percentage of trucks (vehicle weight exceeding $30 \mathrm{kN}$ ) was $14.9 \%$ for all the three years considered with the $90 \%$ of trucks travelling on the right lane only. By assuming as a reference the year 2007, the cumulative number of trucks $\left(N_{t}\right)$ that had travelled on the right lane of the A3 motorway in the north direction only was estimated to be of $2.8 \times 10^{6}$ and $5.31 \times 10^{6}$ at year 2010 and 2012 , respectively.

The surface layer of the investigated pavement consists of porous asphalt with a thickness of $4 \mathrm{~cm}$. The average values of porous asphalt characteristics that were tested are as follows: Marshall stability equal to $6.9 \mathrm{kN}$, indirect tensile strength of $1.95 \mathrm{~N} / \mathrm{mm}^{2}$, volume of air voids equal to $23 \%$, bitumen content of $4.6 \%$ by weight. The grading distribution (\% passing by weight) of the limestone and basalt mineral aggregate used in the asphalt porous is as follows (in brackets are the sieve sizes in $\mathrm{mm}$ ): $100 \%(20), 98.89 \%(15), 55.12 \%(10), 14.28 \%(5)$, 10.39 (2), $6.37 \%$ (0.42), 5.29 (0.18), $4.11 \%(0.075)$.

It is to be stressed that the main scope of this paper is to present a procedure for processing the acquired data and from a statistical view point showing the potential of the SURE method. Therefore more detailed information related to SFC, IRI and MPD is omitted to save space.

\section{Exploratory Analysis}

Given that the longitudinal measurements of the three aforementioned indicators were obtained on the same motorway section but in different times, this needs some questions and assumptions to be discussed before stating the statistical modelling.

When a survey is conducted in a month different from that of the preceding years, this implies that there might be a different amount of time from the last rain during which the pavement is dry. As a result the pavement surface might be cleaner (or less clean) if compared to surface conditions of preceding survey, which might influence the values of measurements even if the pavement temperature is the same. In order to reduce the probability of this type of error, monthly adjustment factors derived from the literature (see Rogers \& Gargett, 1991) were used in this paper for the years 2010 and 2012 by assuming as a reference the month (September) in which the surveys was carried out in the year 2007.

Also, when the surveys are repeated in different times, a second concern is that the initial measurement point 
might be not exactly the same. For detecting the possible presence of this kind of error and correcting it, we applied a cross-covariance analysis to the available data (for a more in depth knowledge see Yaffee \& McGee, 2000; or Shumway \& Stoffer, 2011). Given two time series, say, $y_{1}$ and $y_{2}$ the cross-covariance function is here defined as:

$$
\gamma_{y_{1} y_{2}}(l)= \begin{cases}\frac{1}{N} \sum_{x=0}^{N-|l|}\left[y_{2}(x+l)-\overline{y_{2}}\right]\left[y_{1}(x)-\overline{y_{1}}\right], & l \geq 0 \\ \gamma_{y_{1} y_{2}}(-l), & l<0\end{cases}
$$

where $N$ is the number of points in which the observations have been carried out (in particular, in the present application, observations are taken every $10 \mathrm{~m}$ across a $3600 \mathrm{~m}$ road section, so as $N=360$ ); $x$ denotes the ordered position of points in the series ( $x$ proceeds from 0 to 360 ); $l$ is the unknown parameter that denotes the lag separation between the two time series; $\overline{y_{1}}$ and $\overline{y_{2}}$ are the means of the observed values respectively in $y_{1}$ and $y_{2}$. In order to estimate the lag separation $(l)$ between the two series of spatial data, the aforementioned cross-covariance function was computed and the lag corresponding to the maximum value of this function was used for correcting the aforementioned type of error. Figure 1 shows this procedure for the two series concerning the measurements of $\mathrm{SFC}_{20^{\circ} \mathrm{C}}$ in the years 2007 and 2010 (a lag $=-10 \mathrm{~m}$ was found in this case).

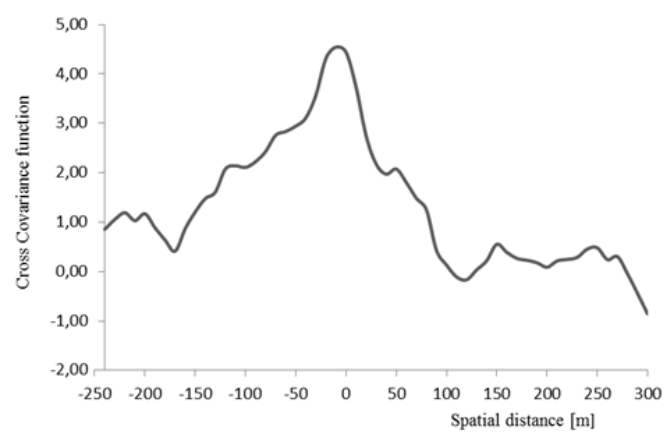

Figure 1. Cross-covariance function vs spatial distance for the $\mathrm{SFC} 20^{\circ} \mathrm{C}$ time series (years 2007 and 2010)

Another additional question is that the wheel track followed by the ERMES along motorway during a survey might be slightly different from that followed in other years. This might imply, for example, that some measurements may have been carried out in points having lateral positions that are slightly different from those of the preceding surveys. For reducing a possible influence attributable to some lateral position errors on the measurements carried out at different times, the average of $\mathrm{SFC}_{20^{\circ} \mathrm{C}}$, IRI, and MPD values over adjacent sections of $50 \mathrm{~m}$ each were computed. It is to be said that as far as the authors are aware the road sections investigated did not receive significant actions of maintenance over time. Then, it was not necessary to remove any of them from the analysis.

In the light of the above considerations and assumptions, a number of $N=72$ observations corresponding to the average values (computed on road sections $50 \mathrm{~m}$ long) of each of the three aforementioned performance indicators $\left(\mathrm{SFC}_{20^{\circ} \mathrm{C}}, \mathrm{MPD}\right.$, and IRI) for each of the three years monitored $(2007,2010$, and 2012) were considered in the statistical analysis.

\section{Methodology}

Seemingly unrelated regression estimation (SURE) method is used to analyse a number of regression functions with correlated error terms. The SURE method uses the correlation between the error terms of the system of equations to improve upon the parameter estimates.

A system of seemingly unrelated regression equations can in general be mathematically represented in the form as follows:

$$
\begin{aligned}
& y_{i 1}=f_{1}\left(\boldsymbol{x}_{i 1}, \gamma_{1}\right)+\varepsilon_{i 1} \\
& y_{i 2}=f_{2}\left(\boldsymbol{x}_{i 2}, \gamma_{2}\right)+\varepsilon_{i 2}
\end{aligned}
$$




$$
y_{i M}=f_{M}\left(\boldsymbol{x}_{i M}, \gamma_{M}\right)+\varepsilon_{i M}
$$

where $y_{i l \ldots . . .} y_{i M}=$ observed performance indicator values; $M=$ number of indicators; $i=$ observation number; $N=$ observations in total; $f_{1}(.) \ldots f_{M}()=$. function that describe the performance indicator's deterioration; $\boldsymbol{x}_{i 1} \ldots \boldsymbol{x}_{i M}=$ explanatory variables vector; $\boldsymbol{\gamma}_{\mathbf{1}} \ldots \boldsymbol{\gamma}_{\boldsymbol{M}}=$ parameters vector that have to be estimated; $\varepsilon_{i 1} \ldots \varepsilon_{i M}=$ error terms. Statistically, it is to be said that there is not direct interaction among the performance indicators. That is, $y_{i 1}$ does not directly determine $y_{i 2}, \ldots \ldots ., y_{i M}$; and $y_{i 2}$ does not directly determine $y_{i 1}, \ldots \ldots ., y_{i M}$, and so on. However this method (i.e., SURE) taking into account the contemporaneous correlation of error terms can provide more efficient parameter estimates.

Denoting the errors terms vector as $\boldsymbol{\varepsilon}_{\mathbf{i}}{ }^{\prime}=\left[\varepsilon_{i l}, \varepsilon_{i 2}, \ldots, \varepsilon_{i M}\right]$, the variance covariance matrix of $\boldsymbol{\varepsilon}_{\mathbf{i}}{ }^{\prime}$ is expressed as:

$$
\sum=\boldsymbol{E}\left[\boldsymbol{\varepsilon}_{\boldsymbol{i}} \boldsymbol{\varepsilon}_{i}^{\prime}\right]=\left[\begin{array}{cccc}
\sigma_{11} & \sigma_{12} & \cdots & \sigma_{1 M} \\
\sigma_{21} & \sigma_{22} & \cdots & \sigma_{2 M} \\
\vdots & \vdots & \vdots & \vdots \\
\sigma_{M 1} & \sigma_{M 2} & \cdots & \sigma_{M M}
\end{array}\right]
$$

where $\sigma_{j k}=$ covariance between the error terms of equations $\mathrm{j}$ and $\mathrm{k}$ in Equation (2) with:

$$
\begin{gathered}
\sigma_{j k}=\frac{\sum_{i=1}^{N}\left(\varepsilon_{i j}-\overline{\varepsilon_{J}}\right)\left(\varepsilon_{i k}-\overline{\varepsilon_{k}}\right)}{N} \\
\overline{\varepsilon_{J}}=\frac{\sum_{i=1}^{N} \varepsilon_{i j}}{N} \\
\overline{\varepsilon_{k}}=\frac{\sum_{i=1}^{N} \varepsilon_{i k}}{N}
\end{gathered}
$$

It is to be noted that whether the deterioration models based on individual performances indicators are assumed to be separate, this implies that these models are unrelated so that $\sigma_{\mathrm{jk}}=0$ for $\mathrm{j} \neq \mathrm{k}$ (the off-diagonal elements are equal to zero).

To estimate the above mentioned joint system of equations, the maximum likelihood estimation (MLE) method is used. A likelihood ratio test (LRT) can also be carried out to determine whether the system model that assumes correlation is more appropriate than separate models. In this respect, more detailed information can be found in Greene (2003). Green (2007) has also developed an estimation procedure.

\section{Analysis of Results}

\subsection{Estimation Results}

The estimation results of the SURE method, obtained by using LIMDEP software (Green, 2007), are reported in Table 3. For a comparison, the results derived from the three models considered separately (SM) are also presented.

Estimation points have the sign expected for all these models: the $\mathrm{SFC}_{20^{\circ} \mathrm{C}}$ decreases as the number of accumulated trucks $\left(N_{t}\right)$ increases; whereas the MPD and IRI increase as the number of trucks increases. These findings are consistent with other relationships of pavement deterioration process contained in the literature. The t-statistic indicates that parameters $\alpha_{1}, \alpha_{2}$, and $\alpha_{3}$, associated respectively to $\mathrm{SFC}_{20^{\circ} \mathrm{C}}, \mathrm{MPD}$, and IRI are statistically different from zero at $90 \%$ confidence level in all three models.

Table 3. Estimation results for the SURE model (applied to the SFC $20^{\circ} \mathrm{C}$, MPD and IRI) and corresponding Separate Models (SM)

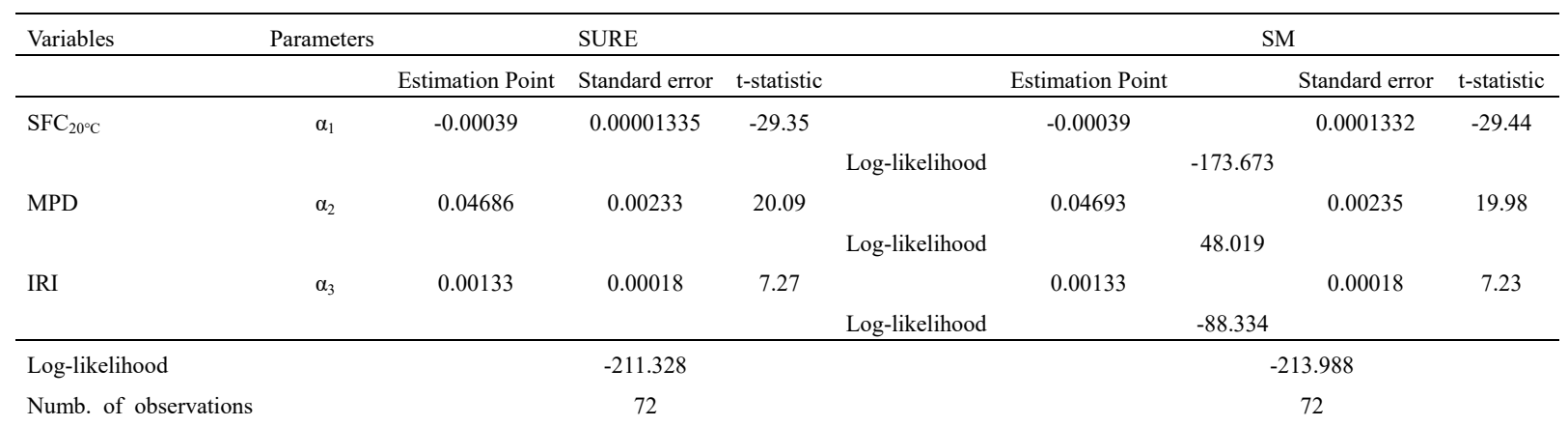


(for each performance

indicator)

$-2(\operatorname{LL} R-\mathrm{LL} U) \quad 5.32$

p-value

The likelihood ratio statistic is $-2(\operatorname{LL} R-\operatorname{LL} U)$, where $\operatorname{LL} R$ and $L L U$ are the log-likelihood values at convergence for uncorrelated and correlated conditions, respectively (Greene 2003). In addition, -2(LLR-LLU) has the chi-square distribution with $k$ degrees of freedom, where $k=M(M-1) / 2$. It is shown in Table 3 , that $\mathrm{LL} R=-173.67+48.02-88.33=-213.99, \mathrm{LL} U=-211.33$, and $-2(\operatorname{LL} R-\mathrm{LL} U)=5.32$. In this particular case with $k=3$, this corresponds to a p-value 0.150 and the null hypothesis cannot be rejected at any significance level less than this value.

\subsection{Forecasting Accuracy}

The system of equations of the pavement deterioration model for estimating the values of the $\mathrm{SFC}_{20^{\circ} \mathrm{C}, \mathrm{MPD} \text { and }}$ IRI over time as a function of the cumulative number of trucks $\left(N_{t}\right)$ is as follows:

$$
\begin{gathered}
\left.S F C_{20^{\circ} \mathrm{C}}=S F C_{20^{\circ} \mathrm{C} \text {, base } \bullet} e_{{ }_{1}{ }_{t}}^{N_{t}}\right) \\
M P D=M P D_{\text {base }}+\alpha_{2} \cdot \log \left(N_{t}\right) \\
I R I=I R I_{\text {base }}+\alpha_{3} \bullet N_{t}
\end{gathered}
$$

where $\alpha_{1=}-0.00039, \alpha_{2}=0.04686$, and $\alpha_{3}=0.00133$ in the case study; with the $\mathrm{SFC}_{20^{\circ} \mathrm{C}}$ expressed numerically but positive values smaller than 100; the MPD in $\mathrm{mm}$; the IRI in $\mathrm{mm} / \mathrm{m}$; the accumulated number of trucks expressed in $\mathrm{N}_{t} / 10^{4}$; and the logarithm is in base $e$ (the system model is valid for $N_{t} \geq 10^{4}$ ).

As an example, using as a possible reference for a comparison the arithmetic mean $\mu$ ( $\mu=\frac{\sum_{i=1}^{N} x_{i}}{N}$ of the sample of measurements $x_{1}, \ldots, x_{n}$ ) one estimates after a cumulative number of trucks $\left(N_{t}\right)$ equal to $2.8 \cdot 10^{6}$ (computed at year 2010 respect to year 2007) and 5.31 $10^{6}$ (computed at year 2012 respect to year 2007) values of $\mathrm{SFC}_{20^{\circ} \mathrm{C}}$ respectively of 49.61 and 44.98 against corresponding average values of 54.51 and 43.72 measured in the field; MPD equal to 1.64 and $1.68 \mathrm{~mm}$ against means of 1.62 and $1.64 \mathrm{~mm}$ based on measurements in the field; and finally IRI equal to 2.59 and $2.92 \mathrm{~m} / \mathrm{km}(\mathrm{mm} / \mathrm{m})$ against means of 2.41 and $2.67 \mathrm{~m} / \mathrm{km}(\mathrm{mm} / \mathrm{m})$ observed in the field. This comparison shows an acceptable level of conformity between the predicted and observed values of aforementioned pavement performance indicators.

\section{Summary and Conclusions}

This research was motivated more especially by the need to individualize a methodological approach that appears to be more appropriate for showing the possible interrelation among different performance indicators while accounting for the full performance of a pavement over time. In particular, the seemingly unrelated regression equations (SURE) method is investigated to capture the deterioration process of pavement indicators considered with correlated error terms.

To achieve the paper's goal, an Italian motorway connecting the cities of Salerno and Reggio Calabria was monitored. Three performance indicators of pavement known as the side force coefficient $\left(\mathrm{SFC}_{20^{\circ} \mathrm{C}}\right)$, the international roughness index (IRI), and the mean profile depth (MPD) were more especially measured in three different time periods on a same section of this motorway.

After an exploratory analysis, a system based on the seemingly unrelated regression estimation (SURE) technique, which accounts for the correlation among the error terms in each seemingly unrelated equation in order to improve the parameter estimates, was developed. Regression parameters were estimated by the Maximum Likelihood Method.

It was found that estimation points have the signs expected: the $\mathrm{SFC}_{20^{\circ} \mathrm{C}}$ decreases as the number of accumulated trucks increases; whereas the MPD and IRI increase as the number of trucks increases. These findings are consistent with other relationships of pavement deterioration process contained in the literature. The $t$-statistic indicates that regression coefficients associated respectively to $\mathrm{SFC}_{20^{\circ} \mathrm{C}}, \mathrm{MPD}$, and IRI are all statistically significant at $90 \%$ confidence level.

The log-likelihood of the SURE model is found to be a bit greater than that of the three separate models (SM). 
Moreover the p-value of 0.15 may lead that the null hypothesis cannot be rejected at any significance level less than this value. This supports that the aforementioned three performance indicators should be jointly considered in the performance of a pavement over time accounting for the correlation among error terms.

The model developed in this paper produces an acceptable level of conformity between the predicted and measured performance measures. Therefore, this can be useful for many application such as the estimation of pavement rehabilitation needs over time, quantifying the performance modifications of pavement due to a variation of traffic demand, individualising the treatment type of a pavement that appears to be more appropriate in relation to a different deterioration process of one or more performance indicators.

Although this paper represents an interesting advancement in the assessment of performance measures of a pavement, more road sections should be investigated for a more consolidated verification of results obtained. However the method followed in the current paper, which is based on the use of the SURE model, represents a considerable potential in analysing jointly different performance indicators. Therefore, research needs to be addressed towards applying this statistical approach for making further developments possible.

\section{Acknowledgments}

The authors would like to thank the Management Agency of Salerno-Reggio Calabria Motorway (ANAS) for providing performance indicators data, and Nicola Nocera (ANAS) for his immense assistance in data acquisition. The contents of this paper reflect the views of authors and do not necessarily reflect the official views or policies of the Motorway Management Agency.

\section{References}

American Association of State Highway and Transportation Officials. (2008). Mechanistic-Empirical Pavement Design Guide. A Manual of Practice. AASHTO, Washington, DC: American Association of State Highway and Transportation Officials.

Anastasopoulos, P. Ch., Mannering, F. L, \& Haddock, J. E. (2012). Random parameters seemingly unrelated equations approach to the postrehabilitation performance of pavements. Journal of Infrastructure Systems, 18(3), 176-182. http://dx.doi.org/10.1061/(ASCE)IS.1943-555X.0000096

Anastasopoulos, P. Ch., Mannering, F. L., \& Haddock, J. E. (2009). Effectiveness and service lives/survival curves of various pavement rehabilitation treatments. FHWA/IN/JTRP-12. Joint Transportation Research Program, Indiana Department of Transportation and Purdue University. Retrieved from http://docs.lib.purdue.edu/cgi/viewcontent.cgi?article $=2640 \&$ context $=$ jtrp

Archilla, A. R. (2006). Repeated measurement data analysis in pavement deterioration modeling. Journal of Infrastructure Systems, 12(3), 163-173. http://dx.doi.org/10.1061/(ASCE)1076-0342(2006)12:3(163)

Archilla, A. R., \& Madanat S. (2001). Estimation of rutting models in combining data from different sources. $\begin{array}{llll}\text { Journal of } & \text { Transportation } & \text { 379-389. }\end{array}$ http://dx.doi.org/10.1061/(ASCE)0733-947X(2001)127:5(379)

Caliendo, C. (2012). Local calibration and implementation of the mechanistic-empirical design guide for flexible pavement design. Journal of Transportation Engineering, 138(3), 348-360. http://dx.doi.org/10.1061/(ASCE)TE.1943-5436.0000328

Caliendo, C., De Guglielmo, M. L, \& Guida, M. (2015). Comparison and analysis of road tunnel traffic accident frequencies and rates using random-parameter models. Journal of Transportation Safety \& Security. Retrieved from http://www.tandfonline.com/doi/abs/10.1080/19439962.2015.1013167

Cantisani, G., \& Loprencipe, G. (2010). Road roughness and whole body vibration: evaluation tools and comfort $\begin{array}{llll}\text { limits. Journal of Transportation } & \text { Engineering, } & 136(9), & \text { 818-826. }\end{array}$ http://dx.doi.org/10.1061/(ASCE)TE.1943-5436.0000143

Fini, E. H., \& Parast M. M. (2012). Effect of pavement type on overlay roughness progression. Journal of Transportation Engineering, 138(12), 1558-1562. http://dx.doi.org/10.1061/(ASCE)TE.1943-5436.0000459

Greene, W. (2003). Econometric Analysis (5th Ed.), Prentice Hall, Upper Saddle River, New Jersey. Retrieved from http://stat.smmu.edu.cn/DOWNLOAD/ebook/econometric.pdf

Greene, W. (2007). Limdep, Version 9.0. Econometric Software Inc., Plainview, NY. http://www.limdep.com

Hilbe, J. M. (2007). Negative Binomial regression. Published in the USA, New York, by Cambridge University Press. Retrieved from www.cambridge.org/9780521198158 
Khraibani, H., Lorino, T., Lepert, P., \& Marion, J. M. (2012). Nonlinear mixed-effects model for the evaluation and prediction of pavement deterioration. Journal of Transportation Engineering, 138(2), 149-156. http://dx.doi.org/10.1061/(ASCE)TE.1943-5436.0000257

Loprencipe, G., \& Cantisani, G. (2013). Unified Analysis of Road Pavement Profiles for Evaluation of Surface

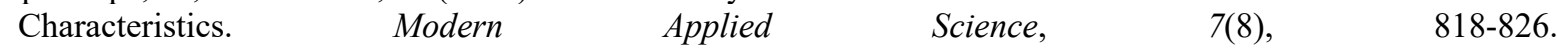
http://www.ccsenet.org/journal/index.php/mas/article/view/27647/17196

Loprencipe, G., Cantisani, G., \& Di Mascio, P. (2015). Global assessment method of road distresses. Life-Cycle of Structural System: Design, Assessment, Maintenance and Management. Proceedings of the $4^{\text {th }}$ International Symposium on Life-Cycle Civil Engineering Systems, CRC Press/Balkema, The Netherlands, ISBN: $\quad 978-113800120-6, \quad 1113-1120 . \quad$ Retrieved from https://www.crcpress.com/Life-Cycle-of-Structural-Systems-Design-Assessment-Maintenance-and-Manage ment/Furuta-Frangopol-Akiyama/9781138001206

Onar, A., Thomas, F., Choubane, B., \& Byron, T. (2006). Statistical mixed effects model for evaluation and prediction of accelerated pavement testing results. Journal of Transportation Engineering, 132(1), 771-780. http://dx.doi.org/10.1061/(ASCE)0733-947X(2006)132:10(771)

Prozzi, J. A., \& Hong, F. (2008). Transportation infrastructure performance modeling through seemingly unrelated regression systems. Journal of Infrastructure Systems, 14(2), 129-137. http://dx.doi.org/10.1061/(ASCE)1076-0342(2008)14:2(129)

Prozzi, J. A., \& Madanat, S. M. (2004). Development of pavement performance models by combining experimental and field data. Journal of Infrastructure Systems, 10(1), 9-22. http://dx.doi.org/10.1061/(ASCE)1076-0342(2004)10:1(9)

Puccinelli, J., \& Jackson, N. (2007). Development of pavement performance models to account for frost effects and their application to mechanistic-empirical design guide. Transportation Research Board, No. 1990, 95-101. http://dx.doi.org/10.3141/1990-11

Rogers, M. P., \& Gargett, T. (1991). A skidding resistance standard for the national road network. Institution of Highway \& Transportation, 38(4), London. Retrieved from http://www.worldcat.org/title/highways-and-transportation-journal-of-the-institution-of-highways-and-trans portation-htta/oclc/10104796

Shumway, R. H., \& Stoffer, D. S. (2011).Time series analysis and its applications. Springer, New York. http://link.springer.com/book/10.1007/978-1-4419-7865-3

Singh, B., \& Ullah, A. (1974). Estimation of seemingly unrelated regressions with random coefficients. Journal of the American Statistical Association, 69(345), 191-195. Retrieved from http://www.tandfonline.com/doi/abs/10.1080/01621459.1974.10480150

Washington, S. P., Karlaftis M. G., \& Mannering F. L. (2011). Statistical and econometric methods of transportation data analysis. Chapman \& Hall/CRC, printed in USA. Retrieved from https://www.crcpress.com/Statistical-and-Econometric-Methods-for-Transportation-Data-Analysis-Second/ Washington-Karlaftis-Mannering/9781420082852

Wooldridge, J. M. (2002). Econometric analysis of cross section and panel data. MIT Press, Cambridge, Massachusetts.

Retrieved

from

https://mitpress.mit.edu/index.php?q=books/econometric-analysis-cross-section-and-panel-data

Yaffee, R. A., \& McGee, M. (2000). An introduction to time series analysis and forecasting. Academic Press, New York. Retrieved from http://store.elsevier.com/An-Introduction-to-Time-Series-Analysis-and-Forecasting/Robert-Yaffee/isbn-978 $0127678702 /$

Zellner, A. (1962). An efficient method of estimating seemingly unrelated regressions and tests for aggregation bias. Journal of the American Statistical Association, 57(298), 348-368. Retrieved from http://www.tandfonline.com/doi/abs/10.1080/01621459.1962.10480664

\section{Copyrights}

Copyright for this article is retained by the author(s), with first publication rights granted to the journal.

This is an open-access article distributed under the terms and conditions of the Creative Commons Attribution license (http://creativecommons.org/licenses/by/3.0/). 